\title{
Sustainable, Continuous Improvement in Online Academic and Information Literacy Support
}

\author{
Sandy Rae, Margaret Hunn and Ana Lobo \\ Library and Learning Services, Griffith University, Brisbane, Australia
}

\section{Abstract}

This paper builds on previous research that evaluated the impact of an embedded online academic and information literacy module into the learning management system (LMS) of a first-year university business course. The research findings concluded that the resource contributed to student success and helped to demonstrate the value of the library at Griffith University to the wider community. Since the original module was embedded into the LMS for a single course in 2014, the provision of these bespoke online modules has expanded. Data has been gathered over the years from 2014 to 2017 on unique users and page views of the modules. Usage has exploded from 4442 page visits by 910 unique users in one course in 2014, to 271,556 page visits by 12,456 unique users in 45 different courses in 2017. Whilst the learning analytics support the continued and increased provision of these resources, other issues around sustainability have arisen and need to be addressed. The aim of this paper is to examine how the use of an e-learning model can help address issues of sustainability that arise as part of supporting an online approach to academic and information literacy support.

\section{Keywords}

Sustainability; model; e-learning; embedded; literacies

\section{Introduction and Background}

Previous research by the authors (Rae \& Hunn, 2015), focussed on the impact of embedding online academic and information literacy modules into a single first-year, undergraduate business course. Their findings showed that overall the resource contributed to student success and that staff and students were satisfied with the student's confidence with academic and information literacy skills, which had further developed as a result of module usage (Rae \& Hunn, 2015). This paper will build on those results by taking an in-depth look into how the online module uptake has grown and how practices have been developed to ensure that the process remains sustainable.

Historically, embedded information literacy skills and academic skills have been taught face to face in lecture time at academic institutions. However, due to the increasing amount of course content to be covered in lecture times, the decrease in teaching weeks with the conversion to the trimester system, and as more students move into the online or hybrid methods of course delivery, embedding online literacy resources has provided an excellent approach to provide academic and information literacy skills support to these students (Maldoni, 2017; Rae \& Hunn, 2015).

The topics covered in each learning resource or module include the key academic and information literacy skills needed to scaffold the completion of the particular course assignment task, with the module positioned directly in the course assessment folder within the LMS, Blackboard. The modules have been employed as a reference point for both undergraduate and postgraduate students, and in several courses utilised in tutorial and workshop sessions by teaching staff to 
explain key literacy skills needed to complete a specific assignment task. Unlike some resources that can be used to only complement the course in question, these learning modules are highly embedded into the teaching and therefore woven into the fabric of the course.

Initial discussions concerning the creation of the learning modules highlighted the need for seamlessly embedding these into courses without them appearing as generic content add-ons, which can often be challenging (Becker, 2014). The challenges around combining an e-learning approach with discipline-embedded resources and breaking down the barriers, continue to be discussed in the literature (McClellan, 2016; Wingate \& Dreiss, 2009). To successfully achieve such seamless embedding of information literacy modules, it was necessary to use the same interface and design established for the rest of the course LMS and for the module to be purposely built for the specific assignment task. Each topic in the module includes a short video with additional narrative and links to further resources, and explicitly focuses on the specific course assignment task. The digital learning objects were personalised as much as possible in order to engage with students in the online environment, as suggested in the New Media Consortium (NMC) Horizon Report (Johnson, Adams Becker, Estrada, \& Freeman, 2014). The literature also suggests that using narrative to form a 'story line' around digital objects as an effective method to create elearning modules that support the pedagogy and technical aspects of reusability (Harden et al., 2011). It has been demonstrated that students are strategic learners (Struyven, Dochy, \& Janssens, 2005) as they will focus on their perceived assessment requirements, therefore, information literacy support provided for their assessment piece will be valued as an active learning tool (Skinner, Mort, Calvo, Drury, \& Molina, 2012; Yoder \& Hochevar, 2005).

Since the original module was created and embedded into the LMS for a single course in 2014, the provision of these individual, assessment specific, online modules has expanded into all levels of undergraduate and postgraduate courses within the Griffith Business School. Academic interest was piqued due to the transition into blended learning offerings at Griffith University demanding equitable access to academic and information literacy support. Data gathered from 2014 to 2017 on unique users and page views of the modules, shows usage has amplified from 4,442 page visits by 910 unique users in one course in 2014, to 271,556 page visits by 12,456 unique users in 45 different courses in 2017. Staff and student feedback on the modules has been exceedingly positive, and it has been demonstrated that usage of the modules does in fact lead to better assessment outcomes for students, as the research indicates (Gunn, Hearne, \& Sibthorpe, 2011; Rae \& Hunn, 2015; Vial, Nikolic, Ros, Stirling, \& Doulai, 2015; Yoder \& Hochevar, 2005). Whilst the learning analytics of the data gathered continues to indicate positive impact on students and so supports the continued and increased provision of these resources, issues around sustainability have arisen.

\section{Issues with Sustainability}

Issues that have been identified with the continued usage of with the learning modules are:

(1) The need for updating each trimester as modules have sections that are pertinent to the assessment of the particular course which may have changed, and the Library web page, databases, tools are being updated rapidly and so click-by-click explanatory videos must be updated to remain relevant and accessible to students. 
(2) Ongoing quality control as more library staff contribute to the creation of modules, a consistent approach to the production must be used.

(3) Time and effort required keeping up with navigating LMS and the extensive technological skills required to develop learning modules and to download, manipulate and collate data on usage statistics required as impact indicators.

(4) Keeping track of files, videos and modules created within the LMS, due to the functionality allowing academic staff to roll over modules into new trimesters or place them into other courses without librarian knowledge.

These issues directly relate to the scalability of the modules across more courses and schools at the university. The modules are limited by an inability to be widely applicable across multi discipline due to the specificity required by particular courses. Discipline-specific modules require much higher levels of customisation to retain relevance to student learning outcomes (Mune et al., 2015). The very element that makes these modules unique and valuable is their bespoke nature which then limits their ability to be scaled across courses and disciplines. For the modules to remain relevant, scaling up the e-learning approach needs to be achieved without the loss of the benefits from the small-scale discipline -embedded approach that has been used in developing these modules.

\section{Methods}

After an extensive search of the literature, a process model, the e-learning Library Skills model (eLLS) was developed that allows for continuous improvement in sustainability with a focus on scalability and reuse or repositioning. A model was chosen in this instance as it helps with planning to meet the complex and often conflicting challenges faced by institutions. A process model can provide a comprehensive understanding of a process and should be descriptive, prescriptive, explanatory and dynamic, allowing the user to make changes when appropriate (Aguilar-Savén, 2004).

The eLLS Model developed, was based on Marshall and Mitchell's (Marshall \& Mitchell, 2002) elearning Maturity Model (eLMM), as shown in Figure 1 below. In turn, Marshall and Mitchell (Marshall \& Mitchell, 2002, p. 4) based their eLMM on the Capability Maturity Model commonly used in software engineering. Marshall (2010) examines the application of the eLMM at a strategic institutional level and at a more fundamental course level. Initially, it is at this fundamental level that the eLMM proves beneficial in developing the eLLS Model.

\begin{tabular}{|ll|}
\hline \multicolumn{1}{c|}{ e-Learning Maturity Model: Framework } \\
\hline Level & Focus \\
\hline 5: Optimising & Continual improvement \\
\hline 4: Managed & Ensuring the quality of both the e-learning resources and student learning outcomes \\
3: Defined & Defined process for development \\
\hline 2: Planned & Clear objectives for e-learning \\
1: Initial & Ad-hoc processes \\
\hline
\end{tabular}

Figure 1. e-Learning maturity model: framework. From an e-Learning maturity model? by S. Marshall and G. Mitchell 2002, proceedings ASCILITE Australasian society for computers in learning in tertiary education. reprinted with permission. 
The framework for Marshall and Mitchell's (Marshall \& Mitchell, 2002) eLMM identifies five maturity levels; Initial, Planned, Defined, Managed and Optimising that can be utilised for 'guiding improvements in e-Learning that move from the realm of an ad hoc process based on individual initiative to an integrated process that delivers demonstrable improvements in areas like student learning' (p. 4). Within each of these five levels, key outcomes of student learning, resource creation, project management and support, and organisational management are examined as key issues for elearning.

One of the advantages of Marshall and Mitchell's (Marshall \& Mitchell, 2002) model is that it is not a 'finished model' (p. 4) but 'simply the basis for an emerging discussion' that assists with 'developing a clearly articulated approach for guiding development of e-Learning resources' (p. 4). Consequently, Marshall and Mitchell's (Marshall \& Mitchell, 2002) model lends itself to adoption and customisation depending on context. With this in mind, the developed eLLS Model utilises the five maturity levels but shifts focus to the key e-learning issues relevant to the library and learning context. As this is a continuous improvement model, the key e-learning issues are relevant at a particular point in time and context and consequently can be customised for particular requirements.

The key e-learning issues faced at this point in time were identified as follows:

- Sustainability, with a focus on scalability and reuse or repositioning (resource creation);

- Pedagogy of student centred approach (outcome);

- Evidence-based practice (engagement).

The selection of these key e-learning issues whilst relevant to a particular context still sit within the broader trends, challenges and developments facing higher education as explored within the NMC Horizon Report: Higher Education Edition (Adams Becker et al., 2017). The report highlights key trends of blended learning design to meet flexibility and accessibility needs; significant challenges such as managing knowledge obsolescence by creating resources that are organised and retrievable independent of technological platform, as well as important developments such as the next generation LMS (Adams Becker et al., 2017).

\section{The eLLS Model}

As a result of our work, the eLLS Model (Table 1, below) has been developed, and improvement is ongoing as we attempt to reach optimisation. Each level is a continuous process, which weaves between Engagement, Resource Creation and Outcome.

\section{Results - Application of the Model}

Using the adapted eLMM, the eLLS model, it can be demonstrated that the development of the online modules has progressed through the levels of the Model and can begin to embrace continuous improvement through implementation of a process model that supports scalability, reusability and discoverability.

\begin{tabular}{cccc}
\hline Level & Engagement & Resource creation & Outcome \\
\hline Initial & $\begin{array}{c}\text { Request meets a specific } \\
\text { teaching goal }\end{array}$ & $\begin{array}{c}\text { Individual resource creation } \\
\text { No formal process for design } \\
\text { or delivery, }\end{array}$ & $\begin{array}{c}\text { Request for resource met } \\
\text { but no evidence gathered }\end{array}$ \\
& & &
\end{tabular}




\begin{tabular}{|c|c|c|c|}
\hline & No consideration of & Educational design not & to determine user \\
\hline Planned & $\begin{array}{c}\text { Requests meet a specific } \\
\text { objective i.e. assessment } \\
\text { support } \\
\text { Academic and student } \\
\text { needs considered }\end{array}$ & $\begin{array}{l}\text { Resource creation is planned } \\
\text { for consistent approach }\end{array}$ & $\begin{array}{c}\text { Feedback sought for user } \\
\text { engagement }\end{array}$ \\
\hline Defined & $\begin{array}{l}\text { Defined process for } \\
\text { requesting resource } \\
\text { creation that meets } \\
\text { academic and student } \\
\text { needs }\end{array}$ & $\begin{array}{l}\text { Process defined for resource } \\
\text { creation including standards } \\
\text { and documented processes. } \\
\text { Educational design } \\
\text { considered }\end{array}$ & $\begin{array}{l}\text { Feedback sought from all } \\
\text { stakeholders to ensure } \\
\text { evidence-based practice }\end{array}$ \\
\hline Managed & $\begin{array}{c}\text { Needs driven pedagogical } \\
\text { approach }\end{array}$ & $\begin{array}{l}\text { Resource creation managed } \\
\text { for quality and sustainability }\end{array}$ & $\begin{array}{l}\text { Feedback sought for } \\
\text { evidence-based practice } \\
\text { and to drive further } \\
\text { engagement and } \\
\text { improvement }\end{array}$ \\
\hline Optimising & $\begin{array}{l}\text { Evidence used to support } \\
\text { engagement that meets } \\
\text { strategic directions of } \\
\text { organisation }\end{array}$ & $\begin{array}{l}\text { Continuous improvement in } \\
\text { quality and sustainability } \\
\text { practices }\end{array}$ & $\begin{array}{c}\text { Evidence used to drive } \\
\text { further engagement and } \\
\text { meet changing strategic } \\
\text { directions }\end{array}$ \\
\hline
\end{tabular}

Table 1. The eLLS model

Retrospectively, initial resource creation was an individual effort that met an ad hoc request reflecting the Initial level of the eLLS. Members of the business team in Library and Learning services developed a module for one firs t-year core business course. As this initial module was developed and adjusted, it evolved through the Planned level. The request met a specific objective of assessment support, and it was created with the help of an educational designer to be consistent with the course LMS look and feel. Feedback was sought from staff and students, learning analytics were collected, and the results of the impact of this resource were published (see Rae \& Hunn, 2015)

As more academics became aware of the resources, more requests were received for different types of bespoke resources to support specific assignments in the Business School. This gave further evidence of operating in the Planned level, as the academics made requests for specific inclusions into the modules created to meet student needs, based on previous iterations of the courses. Library staff involved in the production of the modules and reports rapidly developed knowledge about the new technologies and analytics required. A consistent approach to format the modules was tweaked as the LMS course sites were upgraded, and a formal mechanism for feedback from students was introduced.

As more requests for modules from academics were received, a more defined process was introduced. A request form was developed and sent to all academics in the Business School, along with an exemplar of existing modules. Moving into the Defined level, procedures for library staff were documented for creation of the modules and for the collection of learning analytics. Reports were created each semester or trimester detailing learning analytics data and feedback from students was reported to stakeholders. The reporting of positive student feedback and usage statistics led to greater academic staff demand and engagement. The literature demonstrates that students want to see technology integrated into their courses and are satisfied when it shows a clear 
educational objective and teaching staff like to integrate online content when it shows a clear educational value (Waycott, Bennett, Kennedy, Dalgarno, \& Gray, 2010).

It was at this level that issues of scalability and sustainability materialised and needed to be addressed. At this stage, only a small team consisting of a librarian, two learning advisers and a digital capability officer were working on the modules. The online content had been developed into a more professional product using the software Camtasia and also the university recording studios. Modules and digital learning objects were stored in the LMS and in YouTube and reporting had developed into a more strategic focus, detailing how the modules met organisational goals. However, as more academics in the business school requested modules and academics from other disciplines expressed interest, the very element that made these modules unique and valuable is what made it challenging to scale them across courses and disciplines. The specificity required by particular course convenors to address particular assessment items limited the applicability of the modules across multi disciplines, and the time constraints of existing staff limited the development of more modules.

To address this issue, an inventory of the wide range of resources and digital learning objects (e.g. videos, transcripts, Power Points) that had been created, identified patterns of what was being requested. General digital learning objects relating to the type of assessment being offered were created, and a narrative around the learning object was used to focus on the specific course assessment. This led the modules to still be assessment and course specific but allowed digital learning objects to be more general. Importantly, initiatives and procedures were introduced that included metadata and naming conventions for digital learning objects. Strategic organisational objectives, such as employability and program led course engagement, were incorporated into the resource creation. These procedures indicate movement into the Managed level, taking a pedagogical approach to the modules, as well as seeking guidance from heads of departments as to what course to target for resource development to support assurance of learning obligations. Through new procedures, resource creation is being more effectively managed for quality and sustainability, and feedback received drives further engagement and improvement of the modules moving towards the Optimising level. It should be noted that the Optimising level does not suggest that there is no more to do but rather it is stage of continuous improvement in all aspects of the identified key issues of e-learning that are being addressed.

Using the model has highlighted possible solutions that have emerged to the scalability issues listed earlier. Improving procedures relating to metadata and naming conventions for digital learning objects addresses the issues of scalability, discoverability and reusability. These practices allowed for greater sustainability in resource creation whilst still meeting student and individual academic needs. Library staff have developed their technological skills for ease of editing digital learning objects when changes are made to the library website. Quality control issues will need to be addressed by staff training as more staff and disciplines use these methods of delivering information literacy online.

The development and use of the eLLS Model assisted when progressing to the higher levels for a flexible and accessible pedagogical approach to e-learning. The model has been employed to reflect the workflows with regard to the production of the modules. Engagement procedures are documented to reflect client requests and processes. This leads to the resource creation of the elearning objects required and embedding them into courses. Outcomes are then assessed by 
learning analytics which are distributed back to stakeholders, which in turn leads to greater engagement. By documenting these processes, much greater clarity has been achieved to all aspects of workflows and the Business Team information literacy staff have moved from using ad hoc processes into a streamlined production team, which in turn has decreased production times and enabled increases in outputs. An important outcome of using the eLLS Model is that it has introduced a mindset amongst the Business Team information literacy staff for continuous improvement and a realisation that it is a process that should not be neglected. Engagement drives resource creation and outcomes. The outcome (evidence), in turn, drives further engagement. This has allowed the advancement into higher levels of the model.

\section{Conclusions and Relevance}

A small step into experimentation with service delivery in academic and information literacy modules in the LMS in 2014 has led to a giant leap in the production and usage of these modules in 2017. To sustain this growth and promote continuous improvement, a process model based on an eLMM helps to address issues of sustainability and innovation.

By using the levels demonstrated in the eLLS Model, the specific issues around sustainability in maintaining relevance and scalability across courses in the e-learning arena such as: the need for upgrading, ongoing quality control, staff time and file maintenance have been met in an achievable and appropriate way. It has ensured that a process is being followed and that notwithstanding, a high-quality product is consistently being delivered to students and staff alike. Application of the model has clarified that it is not only the content of delivery of information literacy skills that is important, but the processes around engaging with academic staff, production of a quality product and the follow up on that delivery holds high importance in order to maintain the library's sustainability in this area.

The headway being made in blended learning, as well as the undeniable surge in e-learning, whilst meeting the needs of students with educational content in information literacy, is not something that is going to go away. Ensuring that this process of tailored content development is sustainable and achievable by the Library is as important as ensuring the content is relevant and attaining best practice for staff and students. As the eLLS Model has only been recently introduced further evaluation is required across other teams within in the library and discipline areas to fully assess the potential impact of the model.

\section{Disclosure statement}

No potential conflict of interest was reported by the authors.

\section{Notes on contributors}

Sandy Rae works at Griffith University as a Librarian in Business. She has more than a decade of experience in the field of information services. An advocate for information literacy and e-learning, she has published on embedded information literacy in higher education. Her qualifications include a Master of Applied Science, Library, and Information Management and a Graduate Certificate in Higher Education. ORCID http://orcid.org/0000-0001-9196-0573

Margaret Hunn has worked at Griffith University for the past 19 years as a lecturer in the Business School, before joining the library as a learning adviser. She has a Master of Applied Economics and 
Diploma of Education. Her research interests include higher education and e-learning. ORCID http://orcid.org/0000-0002-4643-3253

$\operatorname{Dr}$ Ana Lobo is a Learning Adviser at Griffith University and has been working in the area of student support, as well as conducting research and teaching at a tertiary level for over 15 years. Ana is passionate about the firs t-year student experience, and was recognised for her dedication to supporting students with success in the Australian Awards for University Teaching in 2014 (OLT) and the IEAA Award for Best Practice/Innovation in International Education in 2013.

\section{References}

Adams Becker, S., Cummins, M., Davis, A., Freeman, A., Hall Giesinger, C., \& Ananthanarayanan, V. (2017). NMC horizon report: 2017 higher education edition. Austin, Texas: The New Media Consortium. Retrieved from https://www.nmc.org/publication/nmcAQ9horizon-report-2017-highereducation-edition/

Aguilar-Savén, R. S. (2004). Business process modelling: Review and framework. International Journal of Production Economics, 90(2), 129-149.

Becker, B. W. (2014). A simple solution to embedding library content into every online course. Behavioral and Social Sciences Librarian, 33(3), 170-173.

Gunn, C., Hearne, S., \& Sibthorpe, J. (2011). Right from the start: A rationale for embedding academic literacy skills in university courses. Journal of University Teaching \& Learning Practice, 8(1). Retrieved from https://ro.uow.edu.au/jutlp/vol8/iss1/6/

Harden, R. M., Gessner, I. H., Gunn, M., Issenberg, S. B., Pringle, S. D., \& Stewart, A. (2011). Creating an e-learning module from learning objects using a commentary or 'personal learning assistant. Medical Teacher, 33. doi:10.3109/0142159x.2011.557104

Johnson, L., Adams Becker, S., Estrada, V., \& Freeman, A. (2014). NMC horizon report: 2014 higher education edition. Austin, TX: The New Media Consortium. Retrieved from http://cdn.nmc.org/media/2014-nmc-horizon-report-he-EN-SC.pdf

Maldoni, A. (2017). A cross-disciplinary approach to embedding: A pedagogy for developing academic literacies. Journal of Academic Language \& Learning, 11(1), A104-A124. Retrieved from http://journal.aall.org.au/index.php/jall/article/view/422/273

Marshall, S. (2010). A quality framework for continuous improvement of e-learning: The e-learning maturity model. Journal of Distance Education (Online), 24(1), 143-165. Retrieved from https://files.eric.ed.gov/fulltext/EJ892382.pdf

Marshall, S., \& Mitchell, G. (2002). An e-Learning maturity model? Proceedings ASCILITE (Australasian Society for Computers in Learning in Tertiary Education) Auckland 2009. 26th Annual ASCILITE International Conference, Auckland, 6-9 December 2009. Retrieved from http://www.ascilite.org/conferences/auckland02/proceedings/papers/173.pdf

McClellan, S. (2016). Teaching critical thinking skills through commonly used resources in courseembedded online modules. College \& Undergraduate Libraries, 23(3), 295-314. Retrieved from https://www.tandfonline.com/doi/abs/10.1080/10691316.2014.987416 
Mune, C., Goldman, C., Higgins, S., Eby, L., Chan, E., \& Crotty, L. (2015). Developing adaptable online information literacy modules for a learning management system. Journal of Library and Information Services in Distance Learning, 9(1-2), 101-118.

Rae, S., \& Hunn, M. (2015). Assessing the impact of embedding online academic and information literacy skills in a first year business course. Evidence Based Library and Information Practice, 10(4), 95-112.

Skinner, I., Mort, P., Calvo, R., Drury, H., \& Molina, M. G. (2012). Some do, some don't: Student use of online writing resources. Proceedings AAEE (Australasian Association of Engineering Education) Melbourne 2012. 23rd Annual Conference of the Australasian Association for Engineering Education 2012: Profession of Engineering Education: Advancing Teaching, Research and Careers. Retrieved from: http://www.aaee.net.au/index.php/resources/summary/9-2012/315-proceedings-of-the23rd-annual-conference-for-the-australasian-association-for-engineering-association

Struyven, K., Dochy, F., \& Janssens, S. (2005). Students perception about evaluation and assessment in higher education; a review. Assessment and Evaluation in Higher Education, 30(4), 331-347.

Vial, P. J., Nikolic, S., Ros, M., Stirling, D., \& Doulai, P. (2015). Using online and multimedia resources to enhance the student learning experience in a telecommunications laboratory within an Australian university. Australasian Journal of Engineering Education, 20(1), 71-80.

Waycott, J., Bennett, S., Kennedy, G., Dalgarno, B., \& Gray, K. (2010). Digital divides? Student and staff perceptions of information and communication technologies. Computers \& Education, 54(4), 1202-1211.

Wingate, U., \& Dreiss, C. (2009). Developing students' academic literacy: An online approach. Journal of Academic Language \& Learning, 3(1), A14-A25.

Yoder, J. D., \& Hochevar, C. M. (2005). Encouraging active learning can improve students' performance on examinations. Teaching of Psychology, 32(2), 91-95. 